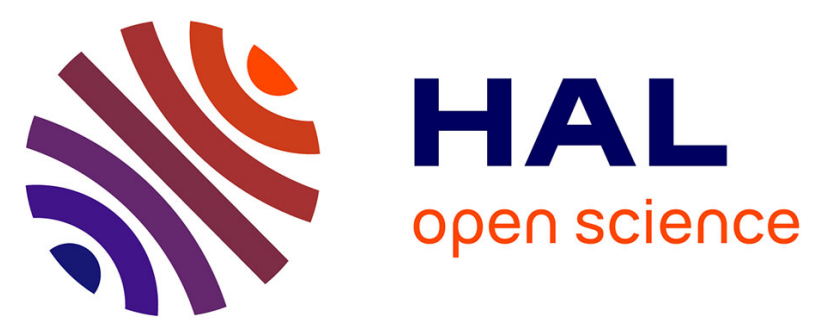

\title{
Cirrus cloud microphysical and optical properties at southern and northern midlatitudes during the INCA experiment
}

Jean-François Gayet, Joëlle Ovarlez, Valery Shcherbakov, Johan Ström, Ulrich Schumann, Andreas Minikin, Frédérique Auriol, Andreas Petzold, Marie Monier

\section{To cite this version:}

Jean-François Gayet, Joëlle Ovarlez, Valery Shcherbakov, Johan Ström, Ulrich Schumann, et al.. Cirrus cloud microphysical and optical properties at southern and northern midlatitudes during the INCA experiment. Journal of Geophysical Research, 2004, 109 (D20), 10.1029/2004JD004803 . hal01896600

\author{
HAL Id: hal-01896600 \\ https://hal.uca.fr/hal-01896600
}

Submitted on 1 Feb 2021

HAL is a multi-disciplinary open access archive for the deposit and dissemination of scientific research documents, whether they are published or not. The documents may come from teaching and research institutions in France or abroad, or from public or private research centers.
L'archive ouverte pluridisciplinaire HAL, est destinée au dépôt et à la diffusion de documents scientifiques de niveau recherche, publiés ou non, émanant des établissements d'enseignement et de recherche français ou étrangers, des laboratoires publics ou privés. 


\title{
Cirrus cloud microphysical and optical properties at southern and northern midlatitudes during the INCA experiment
}

\author{
Jean-François Gayet, ${ }^{1}$ Joëlle Ovarlez, ${ }^{2}$ Valéry Shcherbakov, ${ }^{3,4}$ Johan Ström, ${ }^{5}$ \\ Ulrich Schumann, ${ }^{6}$ Andreas Minikin, ${ }^{6}$ Frédérique Auriol, ${ }^{7}$ Andreas Petzold, ${ }^{6}$ \\ and Marie Monier ${ }^{1}$
}

Received 23 March 2004; revised 6 July 2004; accepted 12 July 2004; published 19 October 2004.

[1] Microphysical and optical measurements were performed in midlatitude cirrus clouds at temperatures between $-33^{\circ} \mathrm{C}$ and $-60^{\circ} \mathrm{C}$ during southern and northern

Interhemispheric Differences in Cirrus Properties From Anthropogenic Emissions (INCA) field experiments carried out at equivalent latitudes $\left(53^{\circ} \mathrm{S}\right.$ and $\left.55^{\circ} \mathrm{N}\right)$ from Punta Arenas in the Southern Hemisphere ( $\mathrm{SH}$, Chile) and Prestwick in the Northern Hemisphere (NH, Scotland). The aim of this paper is to analyze the microphysical and optical properties of cirrus clouds and to compare the results of the two campaigns. Compared with the mean properties of cirrus clouds in $\mathrm{SH}$, the cirrus sampled in $\mathrm{NH}$ were characterized by a greater concentration of ice crystals $\left(2.2 \mathrm{~cm}^{-3}\right.$ versus $1.4 \mathrm{~cm}^{-3}$, respectively) with a lower effective diameter ( $36 \mu \mathrm{m}$ versus $42 \mu \mathrm{m}$, respectively). A significant contrast in extinction coefficient was also evidenced with larger values in $\mathrm{NH}$ than in $\mathrm{SH}\left(0.61 \mathrm{~km}^{-1}\right.$ versus $0.49 \mathrm{~km}^{1}$, respectively), whereas no significant differences in the ice water content were observed $\left(8 \mathrm{mg} \mathrm{m}^{-3}\right)$. The first measurements of the asymmetry parameter obtained in midlatitude cirrus clouds revealed rather uniform particle scattering properties (median $g$ values between 0.76 and 0.78$)$ with small differences between $\mathrm{SH}$ and $\mathrm{NH}(0.770$ versus 0.767 , respectively). No significant differences in crystal shape were evidenced between the two data sets. For similar environmental conditions (i.e., over a similar range of temperature and vertical velocity) and for given values of the relative humidity, the comparisons clearly show distinct differences between the microphysical and optical properties of cirrus clouds sampled in the $\mathrm{SH}$ and $\mathrm{NH}$ field experiments. These differences may be related to the contrasts in cirrus freezing thresholds in terms of relative humidity over ice for onset of clouds, which is about $20 \%$ lower in $\mathrm{NH}$ than in $\mathrm{SH}$, as reported in previous INCA data analyses. Nevertheless, definite conclusions are hampered by the large natural variability of cirrus cloud properties and the limited number of flights performed, not forgetting both the actual freezing mechanisms and potential differences in small-scale dynamical variability, which are still insufficiently understood. INDEX TERMS: 0305 Atmospheric Composition and Structure: Aerosols and particles $(0345,4801) ; 0320$

Atmospheric Composition and Structure: Cloud physics and chemistry; 0360 Atmospheric Composition and Structure: Transmission and scattering of radiation; 0394 Atmospheric Composition and Structure: Instruments and techniques; KEYWORDS: cirrus clouds, microphysics, optical properties

Citation: Gayet, J.-F., J. Ovarlez, V. Shcherbakov, J. Ström, U. Schumann, A. Minikin, F. Auriol, A. Petzold, and M. Monier (2004), Cirrus cloud microphysical and optical properties at southern and northern midlatitudes during the INCA experiment, J. Geophys. Res., 109, D20206, doi:10.1029/2004JD004803.

\section{Introduction}

[2] It is recognized that anthropogenic emissions including aerosols may significantly change the environment via indirect effects on cloud formation and on subsequent

\footnotetext{
${ }^{1}$ Laboratoire de Météorologie Physique, UMR 6016, CNRS, Université Blaise Pascal, Clermont-Ferrand, France.

${ }^{2}$ Laboratoire de Météorologie Dynamique, CNRS, Institut Pierre-Simon Laplace, Ecole Polytechnique, Palaiseau, France.

${ }^{3}$ Institute of Physics, Minsk, Belarus.

Copyright 2004 by the American Geophysical Union. 0148-0227/04/2004JD004803
}

microphysical and radiative properties. Our knowledge of cirrus properties results from several intensive experiments that have been carried out during the last two decades, for example, FIRE [Starr and Wylie, 1990; Randall et al., 1995],

\footnotetext{
${ }^{4}$ Now at Observatoire de Physique du Globe de Clermont-Ferrand, Université Blaise Pascal, Clermont-Ferrand, France.

${ }^{5}$ Institut of Applied Environmental Research, Stockholm University, Stockholm, Sweden.

${ }^{6}$ Institut für Physik der Atmosphäre, Deutsches Zentrum fur Luft- und Raumfahrt Oberpfaffenhofen, Weßling, Germany.

${ }^{7}$ Laboratoire d'Optique Atmosphérique, UMR 8518, CNRS, Université de Lille 1, Villeneuve d'Ascq, France.
} 
Table 1. Payload of the DLR Falcon Aircraft During INCA

\begin{tabular}{|c|c|c|c|c|}
\hline Instrument & Measurement & Range & Inlet & Label $^{\mathrm{a}}$ \\
\hline \multicolumn{5}{|c|}{ Cloud Microphysical Properties } \\
\hline PMS-PCASP & Aerosol size distribution & $0.12-3.5 \mu \mathrm{m}$ & Wing mount & DLR \\
\hline PMS-FSSP-300 & Aerosol/crystal size distribution & $0.3-20 \mu \mathrm{m}$ & Wing mount & DLR \\
\hline PMS-2DC & Crystal size distribution & $25-800 \mu \mathrm{m}$ & Wing mount & LaMP \\
\hline Polar nephelometer & Scattering phase function & $3-800 \mu \mathrm{m}$ & Wing mount & LaMP \\
\hline Hygrometer & Cloud water content & $0.002-1 \mathrm{~g} / \mathrm{kg}$ & CVI probe & SU \\
\hline \multicolumn{5}{|c|}{ Interstitial/Out-Of-Cloud Aerosol Properties } \\
\hline CPC 1 & Aerosol number density & $\mathrm{D}>10 \mathrm{~nm}$ & Aerosol probe & DLR \\
\hline СРC 2 & Aerosol number density & $\mathrm{D}>15 \mathrm{~nm}$ & Aerosol probe & DLR \\
\hline DMPS & Aerosol size distribution & $0.02-0.15 \mu \mathrm{m}$ & Aerosol probe & DLR \\
\hline PMS-PCASP & Aerosol size distribution & $0.12-3.5 \mu \mathrm{m}$ & Aerosol probe & DLR \\
\hline Filter samples & Particle composition & $\mathrm{D}>0.2 \mu \mathrm{m}$ & Aerosol probe & DLR \\
\hline Volatility & Thermal properties of particles & $0.02-2 \mu \mathrm{m}$ & Aerosol probe & DLR \\
\hline Black carbon & Differential absorption & $>0.1 \mathrm{~g} \mathrm{~m}^{-3}$ & Aerosol probe & DLR \\
\hline \multicolumn{5}{|c|}{ Crystal Residual Properties } \\
\hline CPC 1 & Residual number density & $\mathrm{D}>10 \mathrm{~nm}$ & CVI probe & SU \\
\hline СРC 2 & Residual number density & $\mathrm{D}>15 \mathrm{~nm}$ & CVI probe & SU \\
\hline DMPS & Residual number density & $0.02-0.15 \mu \mathrm{m}$ & CVI probe & SU \\
\hline PMS-PCASP & Residual number density & $0.12-3.5 \mu \mathrm{m}$ & CVI probe & SU \\
\hline Filter samples & Residual particle composition & $\mathrm{D}>0.2 \mu \mathrm{m}$ & CVI probe & SU \\
\hline Volatility & Thermal properties of particles & $0.02-2 \mu \mathrm{m}$ & CVI probe & SU \\
\hline Black carbon & Differential absorption & $>0.1 \mathrm{~g} \mathrm{~m}^{-3}$ & CVI probe & SU \\
\hline \multicolumn{5}{|c|}{ Trace Gas Concentrations } \\
\hline Hygrometer & Water vapor mixing ratios & $3-5000 \mathrm{ppm}$ & Gas inlet & LMD \\
\hline & Nitrogen oxide mixing ratio & $0.005-25 \mathrm{ppb}$ & Gas inlet & DLR \\
\hline NOy & Total reactive nitrogen gases & $0.05-25 \mathrm{ppb}$ & Gas inlet & DLR \\
\hline Ozone monitor & Stratospheric tracer & $10-1500 \mathrm{ppb}$ & Gas inlet & DLR \\
\hline Carbon monoxide & Tropospheric tracer & $5-500 \mathrm{ppb}$ & Gas inlet & DLR \\
\hline
\end{tabular}

${ }^{a}$ DLR, Deutsches Zentrum für Luft- und Raumfahrt (Institut für Physik der Atmosphäre); LaMP, Laboratoire de Météorologie Physique (UMR/CNRS 6016, Université Blaise Pascal); SU, Stockholm University (Institute of Applied Environmental Research); and LMD, Laboratoire de Météorologie Dynamique (CNRS/IPSL, Ecole Polytechnique).

ICE'89 [Raschke et al., 1990], EUCREX'94 [Sauvage et al., 1999], AEROCONTRAIL [Schröder et al., 2000], and SUCCESS [Lawson et al., 1998]. Because of the unknown duration between the formation of the particles and the in situ observations performed in the cirrus environment, which is usually turbulent and rapidly changing, the observations do not describe the conditions at the time of ice nucleation. Therefore ice nucleation processes are difficult to observe in the atmosphere. While the aerosol effects on warm cloud formation are relatively well documented and understood, very little is known about the role of aerosols in cirrus clouds [Penner et al., 1999]. Possible indirect effects on the microphysical properties of cirrus sampled near flight corridors were evidenced by Ström and Ohlsson [1998] and Kristensson et al. [2000]. In polluted cirrus with elevated amounts of light absorbing material in the ice crystals (presumably engine soot) they found elevated ice particle numbers and reduced mean particles sizes. Aircraft emissions may have caused long-term increases observed in cirrus occurrence [Boucher, 1999; Zerefos et al., 2003] with a possibly significant impact on regional radiative forcing. As anthropogenic emissions are distributed unevenly over the globe, the effects on aerosols and clouds may vary geographically. Consequently the European project Interhemispheric Differences in Cirrus Properties From Anthropogenic Emissions (INCA) [Ström et al., 2001] was designed to provide a unique set of data which allows for direct comparison of cirrus cloud properties in pristine and polluted environments. Cirrus cloud microphysical and optical properties were measured along with aerosol prop- erties and gas traces in both hemispheres during the same season (local autumn in 2000). The observations were carried out at midlatitudes at equivalent latitudes from Punta Arenas $\left(53.12^{\circ} \mathrm{S}\right.$ and $70.88^{\circ} \mathrm{W}$, South of Chile, hereafter $\mathrm{SH})$ and from Prestwick $\left(55.51^{\circ} \mathrm{N}\right.$ and $4.60^{\circ} \mathrm{W}$, Scotland, hereafter $\mathrm{NH}$ ). It should be stressed that the $\mathrm{SH}$ and $\mathrm{NH}$ abbreviations (southern and northern hemispheres respectively) do not imply that we claim that the data represent any global hemisphere means. The same innovative instrumentation (see detailed description in Table 1) was operated onboard the German DLR (Deutsches Zentrum für Luftund Raumfahrt) Falcon aircraft. A Mobile Aerosol Raman Lidar (MARL) was also operated by AWI (Alfred Wegener Institute for Polar and Marine Research) in Punta Arenas and Prestwick [Immler and Schrems, 2002]. Recent works on the interpretation of INCA data have already provided some insight into basic properties of the troposphere and formation mechanisms of upper tropospheric cirrus clouds. For instance, trace gas measurements performed during INCA have been reported by Baehr et al. [2003]. The uptake of reactive nitrogen species on ice crystals in cirrus clouds has been investigated by Ziereis et al. [2004]. The ambient concentrations of nonvolatile condensation nuclei at $10-12 \mathrm{~km}$ altitude are approximately $35 \mathrm{~cm}^{-3}$ in $\mathrm{NH}$ and $12 \mathrm{~cm}^{-3}$ in SH [Minikin et al., 2003]. Therefore the formation of cirrus clouds could potentially be influenced by insoluble aerosols from natural and anthropogenic sources. Analyses of residual particles [Seifert et al., 2003] support the crucial role of size-dependent aerosol chemistry in determining the freezing properties of aerosol particles. 
Distinct interhemispheric differences have been evidenced in cirrus cloud freezing thresholds with onset of clouds in $\mathrm{NH}$ which is some $20 \%$ lower than in $\mathrm{SH}$ and consistent with analyses of relative humidity [Ström et al., 2003; Haag et al., 2003] measured during INCA [Ovarlez et al., 2002]. Differences in aerosol chemical or morphological properties are suggested as constituting the most likely cause for the observed difference in freezing thresholds. The dynamical variability of vertical air motions on the mesoscale has been shown to play a key role in controlling cirrus properties [Kärcher and Ström, 2003].

[3] In this paper the results of microphysical and optical measurements of midlatitude cirrus clouds sampled during INCA will be presented in terms of mean properties. The interhemispheric differences between $\mathrm{SH}$ and $\mathrm{NH}$ field experiments will then be discussed with emphasis on the relationships with the relative humidity. The instruments used for the in situ observations are presented first, together with the evaluation of the measurement errors.

\section{Instrument Description and Measurements}

[4] In this study three instruments were used to assess microphysical and optical properties of cirrus clouds: (1) the PMS FSSP-300 operated by the DLR, (2) the PMS 2D-C and (3) the polar nephelometer probes, both operated by the LaMP. The combination of these three independent techniques provides a description of particles within a range of diameters varying from a few micrometers (typically $3 \mu \mathrm{m}$ ) to $800 \mu \mathrm{m}$.

\subsection{Microphysical Measurements}

\subsubsection{Instrumentation}

[5] The PMS FSSP-300 optical particle counter measures particles ranging from 0.3 to $20 \mu \mathrm{m}$ in diameter [Baumgardner et al., 1992]. In the present study particles larger than $3 \mu \mathrm{m}$ diameter were assumed to be ice crystals. Coincidence effects on particle sizing were not taken into account during data processing under the hypothesis that these effects do not significantly affect the ice crystal size spectra [Baumgardner et al., 1992]. Evidence for aspherical small ice particles measured during INCA with a typical asymmetry parameter of 0.77 has been highlighted by Gayet et al. [2002a]. The scattering at forward angles from aspherical particles is extremely complex and several attempts have been made to assess the corresponding probe size response [Borrmann et al., 2000; Arnott et al., 2000]. Bearing in mind the work by Gayet et al. [2002a], which considered the calibration proposed by Borrmann et al. [2000], the size calibration of the last channel has been refined. Therefore the upper size limit of the FSSP-300 in this study is actually $21.8 \mu \mathrm{m}$ thus providing better overlapping with the first channel of the 2D-C probe in terms of particle concentration, extinction and ice water content. The bulk quantities were calculated assuming spherical particles with a density of $0.9 \mathrm{~g} \mathrm{~cm}^{-3}$. Since no large ice crystals (D $>\sim 1 \mathrm{~mm}$ ) were detected during most of the cirrus INCA observations, shattering on the probe tips [Heymsfield and Miloshevich, 1995; Gayet et al., 2002a] did not significantly affect the measured concentration.

[6] The PMS 2D-C probe provides information on crystal size and shape for the size range $25-800 \mu \mathrm{m}$. The method of data processing used in this study has already been described in detail by Gayet et al. [1996]. We recall that, at $1 \mathrm{~Hz}$ frequency, the method provides a size spectrum distributed over 32 channels (each with $25-\mu \mathrm{m}$ resolution in the given size range) from which the usual microphysical parameters are deduced: ice particle concentration, mean particle size, and ice water content. Partial images were rejected from the calculations and the sampling surfaces were derived accordingly [Heymsfield and Parrish, 1978]. This technique was used since no large particles $(\mathrm{D}>1 \mathrm{~mm})$ were detected in INCA cirrus clouds during most of the flights. In order to improve the statistical significance for low particle concentrations a 5-s running mean was applied. Irregular ice particles were the most predominant crystal shape sampled in midlatitude cirrus clouds during INCA, therefore the bulk parameters were calculated assuming the following surface equivalent diameter equations [Heymsfield, 1972]:

$$
\left(\mathrm{A}<0.049 \mathrm{~mm}^{2}\right) \quad \mathrm{d}^{\mathrm{eq}}=0.82 \mathrm{~A}^{0.48}
$$

and [Locatelli and Hobbs, 1974]:

$$
\left(\mathrm{A}>0.049 \mathrm{~mm}^{2}\right) \quad \mathrm{d}^{\mathrm{eq}}=0.560 \mathrm{~A}^{0.32}
$$

[7] For these empirical relations, $d^{e q}$ are expressed in millimeters and $A$ in square millimeters. Because the sensitivity of the probe to small particles decreases with airspeed (i.e., $\sim 170 \mathrm{~m} / \mathrm{s}$ with the Falcon aircraft), the six first channels (up to $150 \mu \mathrm{m}$ ) were corrected according to the results of Baumgardner and Korolev [1997]. We therefore assume that these corrections also take into account the miss and/or undersizing of the particles evidenced by Strapp et al. [2001].

\subsubsection{Measurements and Error Evaluation}

[8] Because of the overlap in respective size measurements of the FSSP and 2D-C probes, the microphysical parameters derived from these PMS probes were obtained by adding the contributions of each instrument. The parameter definitions used in this study are the following: (i) Ice particle concentration (Conc), (ii) Extinction coefficient (Ext), (iii) Ice water content (IWC) and (iv) effective diameter $($ Deff $)$. The latter was calculated using the following equation:

$$
D e f f=A \times I W C / E x t
$$

with Deff expressed in $\mu \mathrm{m}, I W C$ in $\mathrm{g} / \mathrm{m}^{3}$ and $E x t$ in $\mathrm{km}^{-1}$ and $A=3000 \mathrm{~mm}^{3} / \mathrm{g}$. We note in passing that the extinction coefficient can also be inferred from the polar nephelometer measurements (see below).

[9] The inherent shortcomings concerning probes and data processing seriously limit the accuracy of derived microphysical parameters as exemplified in Table 2. The rough estimates of random uncertainties (mostly based on published literature) include statistical errors related to sampling statistics, noise errors mainly due to sampling volume determination, and uncertainties from assumptions in the inversion of the PMS probe data (shape, density of particles, airspeed corrections, etc.). These estimates (see detailed calculations in Appendix A) were made for a 
Table 2. Random Uncertainty Estimates of $1 \mathrm{~s}$ Mean Values on Microphysical and Optical Parameters for Two Particle Concentrations: $\mathrm{A}\left(5 \mathrm{~cm}^{-3}\right)$ and $\mathrm{B}\left(0.5 \mathrm{~cm}^{-3}\right)$

\begin{tabular}{|c|c|c|}
\hline Parameter & Uncertainty A, \% & Uncertainty $\mathrm{B}, \%$ \\
\hline \multicolumn{3}{|l|}{ Particle concentration } \\
\hline FSSP $-300^{\mathrm{a}}$ & 30 & 75 \\
\hline $2 \mathrm{D}-\mathrm{C}^{\mathrm{b}}$ & 50 & 75 \\
\hline \multicolumn{3}{|l|}{ Particle size } \\
\hline FSSP $-300^{\mathrm{a}}$ & 35 & 35 \\
\hline $2 \mathrm{D}-\mathrm{C}$ & 25 & 25 \\
\hline \multicolumn{3}{|l|}{ Extinction coefficient } \\
\hline $\mathrm{PMS}^{\mathrm{a}, \mathrm{c}}$ & 60 & 85 \\
\hline Polar nephelometer ${ }^{\mathrm{d}}$ & 25 & 25 \\
\hline \multicolumn{3}{|l|}{ Ice water content } \\
\hline $\mathrm{PMS}^{\mathrm{a}, \mathrm{c}}$ & 75 & 100 \\
\hline \multicolumn{3}{|l|}{ Asymmetry parameter } \\
\hline Polar nephelometer ${ }^{d}$ & 4 & 4 \\
\hline
\end{tabular}

${ }^{\mathrm{a} B a u m g a r d n e r ~ e t ~ a l . ~[1992] . ~}$

${ }^{\mathrm{b}}$ Gayet et al. [1996].

${ }^{c}$ PMS means FSSP-300 and 2D-C

${ }^{\mathrm{d}}$ Gayet et al. [2002b].

typical particle concentration during INCA of $5 \mathrm{~cm}^{-3}$ and for a small particle concentration $\left(0.5 \mathrm{~cm}^{-3}\right)$, both with a sample duration of $5 \mathrm{~s}$. As sampling statistical errors bear greater importance for lower particle concentration, the PMS probe data have considerably higher total uncertainties (75\% to $100 \%)$. These errors are important in particular for the individual data points, but far smaller when considering averages over a longer period.

\subsection{Optical Measurements}

[10] The polar nephelometer [Gayet et al., 1997] measures the scattering phase function of an ensemble of cloud particles (i.e., water droplets or ice crystals or a mixture of these particles from a few micrometers to about $800 \mu \mathrm{m}$ diameter), which intersect a collimated laser beam near the focal point of a parabolic mirror. The light scattered at polar angles from $\pm 3.49^{\circ}$ to $\pm 169^{\circ}$ is reflected onto a circular array of 44 photodiodes. It should be noted that the measurements at small forward and backward scattering angles $\left(\theta<15^{\circ}\right.$ and $\left.\theta>162^{\circ}\right)$ were not available because of light pollution caused by residual light diffraction at the edges of the laser beam. The laser beam is provided by a high-power $(1.0 \mathrm{~W})$ multimode laser diode operating at $\lambda=$ $804 \mathrm{~nm}$. The data acquisition system of the airborne version of the polar nephelometer is designed to provide a continuous sampling volume by integrating the measured signals of each detector at a selected period. For instance the sampling volume $(v)$ is determined by the sampling surface (10-mm long and 5-mm diameter beam) multiplied by the aircraft speed (Falcon cruise speed of approximately $170 \mathrm{~m} / \mathrm{s}$ ), that is, $850 \mathrm{~cm}^{3}$ for an acquisition frequency of $10 \mathrm{~Hz}$. The detection threshold may thus be considered as being close to one particle per liter at this frequency.

[11] Direct measurement of the scattering phase function allows particle types (water droplets or ice crystals) to be distinguished and calculation of the optical parameters to be derived (extinction coefficient and asymmetry parameter, see Gayet et al. [2002b]). Derivation of these parameters requires integration of the scattered light over the scattering angle from $0^{\circ}$ to $180^{\circ}$. With the present version of the polar nephelometer, integration of the measurements is impractical for small angles relative to straight forward and back- ward directions. Therefore we experimentally determined (from water cloud samplings, see Gayet et al. [2002b]) the relationship between the extinction coefficient derived from the PMS measurements and relative values from the integral (from $15^{\circ}$ to $162^{\circ}$ ) of the volume scattering cross section measured by the polar nephelometer (assuming non-lightabsorbent particles at the considered wavelength: $804 \mathrm{~nm}$ ). For water clouds the accuracy of the extinction derivation may be estimated at $15 \%$ according to the usual PMS FSSP probe accuracy [Baumgardner, 1983]. For ice particles (assumed to be randomly oriented and nonabsorbent) the same relationship is assumed to be valid. The accuracy concerning extinction was estimated at $25 \%$ from theoretical results which consider observed variations of the asymmetry parameter (i.e., from 0.75 to 0.85 ).

[12] The asymmetry parameter $(g)$ was determined according to the method of Gerber et al. [2000]. This method assumes that the diffraction and refraction components of scattered light at small scattering angles $\theta<15^{\circ}$ can be separated. The subsequent ratio $f$ of the diffracted portion of the scattered light to the total scattered light was determined for nonabsorbent large spheres to be $f=0.56$ by using Mie calculations and by assuming typical measured water droplet spectra. The $g$ values thus estimated from the scattering phase functions for water droplet cloud segments were compared with those calculated by Mie theory for the corresponding FSSP mean droplet size spectra and were found to agree to within $2 \%$. Without any a priori information concerning the water phase of cloud particles, the value of $f=0.56$ is assumed even for ice particles. In fact, this value is close to the average value which can be estimated from the theoretical results of Takano and Liou [1995] obtained for a variety of ice crystal shapes. Nevertheless, because of deficiencies in theoretical approaches, particularly concerning irregular shaped ice crystals, significant uncertainties may remain in the $g$ value determination (about 4\% [see Garrett et al., [2001]), however the relative fluctuations of this parameter probably reflect the actual cloud optical properties.

[13] The polar nephelometer may be seen to give a more accurate extinction measurement than the PMS probes (see Table 2) since: (i) this measurement is an integral value, and (ii) statistical errors are considerably reduced. Comparison between quantities inferred from the polar nephelometer and the PMS probes shows a noteworthy relationship [Gayet et al., 2002a; Shcherbakov et al., 2004]. The slope parameters derived from the two systems agree almost perfectly and the dispersion of the data points is within the uncertainties in Table 2. These results may validate our assumptions in the inversion of the PMS probe data and suggest that the measurements available are reliable for ongoing comparison between the results from the $\mathrm{SH}$ and $\mathrm{NH}$ campaigns [see also Shcherbakov et al., 2004].

\subsection{Other Measurements}

[14] Water vapor, temperature and vertical airspeed measurements were also used in this study. Water vapor measurements were obtained with a specially designed frost point hygrometer [Ovarlez et al., 2000] which has shown its ability to provide reliable measurements in high-humidity conditions at low temperature during POLINAT2. The unheated inlet is housed in a modified Rosemount-Goodrich 
a)

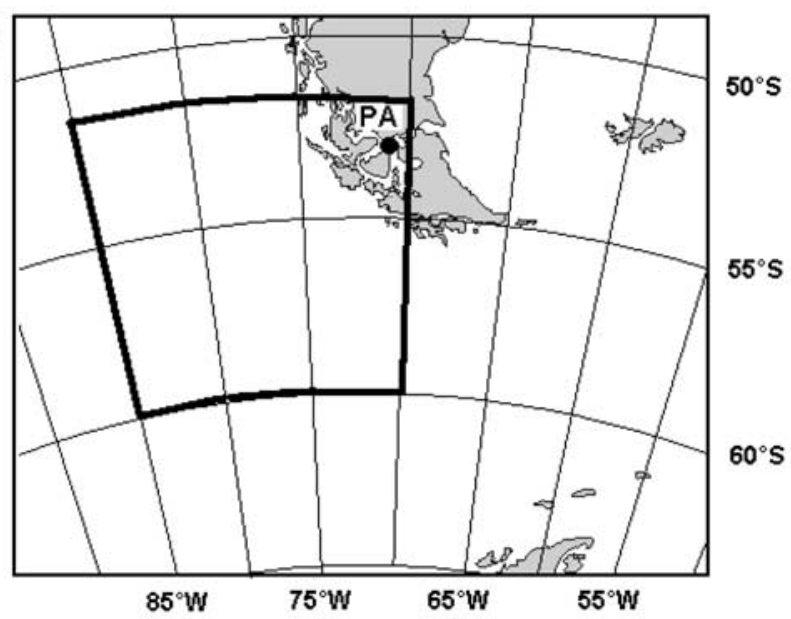

b)

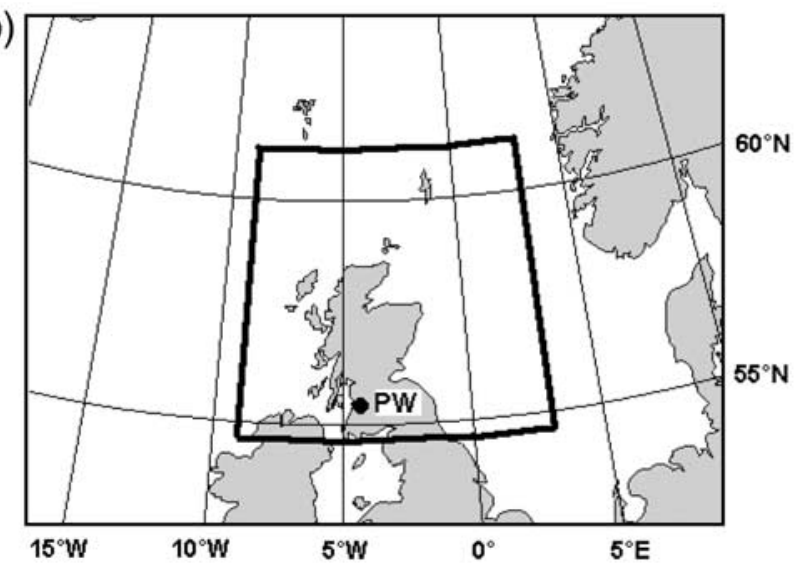

Figure 1. Measurement area and airport of aircraft deployment for (a) the 11 flights made from Punta Arenas (PA) in March and April 2000 and (b) the 9 flights carried out from Prestwick (PW) in September and October 2000.

probe located on the top of the fuselage. Details on the measurement of the relative humidity and accuracy were discussed by Ovarlez et al. [2002]. The relative uncertainty of $\mathrm{RHi}$ is estimated to be better than $7 \%$ ( 2 standard deviations) and the effect of evaporation of small ice crystal and water-rich aerosol particles in the air inlet is below $1 \%$. The Falcon temperature measurements were made with a Rosemount total temperature probe located underneath the nose of the fuselage. The static air temperature was calculated by the usual method and the uncertainty of $T$ was found to be better than $\pm 0.5 \mathrm{~K}$. The derivation method of vertical airspeed from the Falcon aircraft measurements has been described by Bögel and Baumann [1991]. An error of $\pm 10 \mathrm{~cm} / \mathrm{s}$ for mean value within a flight path of $200 \mathrm{~km}$ is generally expected (R. Baumann, private communication, 2003). Trace gas measurements performed during INCA were discussed by Baehr et al. [2003].

\section{Cloud Sampled and Database}

[15] Figures $1 \mathrm{a}$ and $1 \mathrm{~b}$ show the research areas and the general locations of the 11 flights undertaken in March and April (SH field experiment) and of 9 flights carried out in September and October (NH field experiment) respectively. The cirrus cloud data obtained during the test flight from
Oberpfaffenhofen (Germany) just prior to the $\mathrm{NH}$ field experiment are included in the $\mathrm{NH}$ data set.

[16] Direct comparison between the results of both data sets could obviously be biased by different factors like the flight patterns, meteorological situations and the relative fraction of types of sampled clouds. The sampling approach has been described elsewhere [Kärcher and Ström, 2003]. In most of the cases, the flight patterns consisted of climbing to high altitudes above the main cloud layer and then performing several flight legs at different levels of 10 15 min duration within the cloud. The flight legs were mostly oriented perpendicular or parallel to the mean wind at cirrus altitude. Therefore any possible influence of the flight procedure on the results is probably minimized. Several types of cirrus were sampled including: frontal (cold and warm) cirrus, jet stream cirrus, cirrocumulus, orographic wave cirrus, anvil blow-off cirrus and some contrails during the $\mathrm{NH}$ experiment. As a whole, these clouds were sampled under similar thermodynamic conditions as shown in Figure 2 which displays the two frequency distributions of in-cloud temperatures. Except for a few more data points with temperatures below $-60^{\circ} \mathrm{C}$ in the $\mathrm{NH}$ campaign, the temperature distributions are very similar in the two campaigns, with mean values of $-46.4^{\circ} \mathrm{C}(\mathrm{SH})$ and $-46.0^{\circ} \mathrm{C}(\mathrm{NH})$. In terms of dynamic properties (and subsequent cooling rates) the frequency distributions of the vertical wind component $(w)$ (see Figure 3) also exhibit very similar distributions with a symmetrical shape centered on zero $w$ value (mean values of $0.05 \mathrm{~m} / \mathrm{s}$ and $0.00 \mathrm{~m} / \mathrm{s}$ for the SH and NH experiments respectively). The above data were cleared of rapid vertical transport cases. These particular cases include orographic wave cirrus over Punta Arenas on 13 April 2000 and an anvil blow-off cirrus on 12 October 2000 , and these cases exhibit high particle concentrations (up to $100 \mathrm{~cm}^{-3}$ [Gayet et al., 2002c]) significantly much higher than the median particle concentration observed in

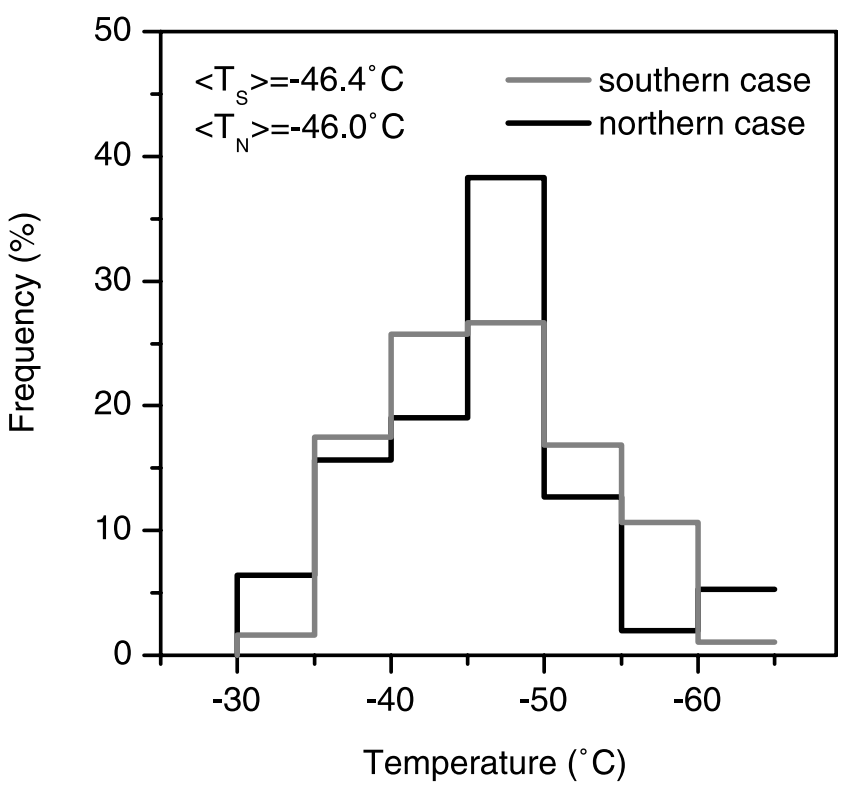

Figure 2. Frequency distributions of the in-cloud temperature measured during the Southern Hemisphere (SH) and Northern Hemisphere (NH) field experiments. 


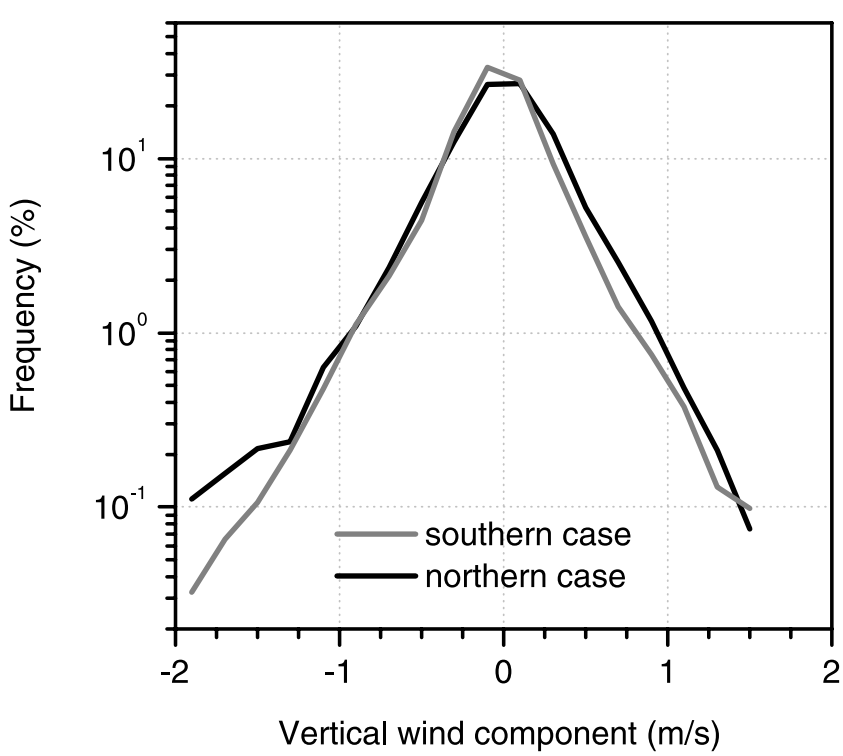

Figure 3. Frequency distributions of the number of incloud data points measured during the $\mathrm{SH}$ and $\mathrm{NH}$ field experiments versus the vertical airspeed.

the other cases. In summary the distributions of $w$ and $T$ are remarkably similar in both field campaigns. Hence, as also reported by Kärcher and Ström [2003], the two field campaigns were performed under comparable meteorological situations.

[17] Some supercooled water droplets (including possibly some frozen spherical particles) were detected by the polar nephelometer for temperatures above $-33^{\circ} \mathrm{C}$. Therefore the analysis was restricted to data collected below that temperature. The in-cloud criterion was defined on the base of the extinction coefficient values derived from the polar nephelometer measurements. Measurements were classified as incloud case when the extinction coefficient was higher than a threshold of $0.05 \mathrm{~km}^{-1}$, which roughly corresponds to a concentration of ice particles of $0.1 \mathrm{~cm}^{-3}$ with a diameter of $3 \mu \mathrm{m}$. Hence very small particle number densities (down to $3 \times 10^{-4} \mathrm{~cm}^{-3}$ ) evidenced by the CVI during INCA [Kärcher and Ström, 2003] were not considered in this study. For the same reason, this analysis probably does not include the subvisible cirrus clouds which were observed from Lidar measurements in particular during the $\mathrm{NH}$ campaign [Immler and Schrems, 2002]. The data set used in this study, with $1-\mathrm{Hz}$ time resolution, represents 32214 data points from the $\mathrm{SH}$ field campaign and 21664 data points in the $\mathrm{NH}$, or about $5,500 \mathrm{~km}$ and $3,700 \mathrm{~km}$ total length of in-cloud flight, respectively.

[18] The microphysical and optical properties of the midlatitude cirrus clouds sampled during INCA are presented below in terms of their mean properties and the differences between the $\mathrm{NH}$ and $\mathrm{SH}$ campaigns in particular in relation to relative humidity.

\section{Results}

\subsection{Results on Mean Microphysical and Optical Properties}

[19] Table 3 summarizes the median values and quartiles of the distributions of the microphysical and optical param- eters of midlatitude cirrus clouds sampled during INCA for both field experiments and for three ranges of temperature binned into $10^{\circ} \mathrm{C}$ intervals around $-38^{\circ} \mathrm{C},-48^{\circ} \mathrm{C}$ and $-58^{\circ} \mathrm{C}$, respectively, and for the sum of all data. Examination of the results in Table 3 shows that the microphysical properties of the midlatitudes cirrus clouds are in accordance with the results from previous works in terms of both, the median values and the quartiles. We refer to the results on microphysical parameters collected in a variety of cirrus types, locations and time of year summarized by Heymsfield and McFarquhar [2002]. It should be pointed out that most of these referenced results do not consider the contribution of small ice crystals. According to our investigations, small ice crystals with $\mathrm{d}<20 \mu \mathrm{m}$ (measured by the FSSP-300) represent about $8 \%$ of the $I W C$ percentage and about $35 \%$ of the extinction percentage respectively. The results in Table 3 show, as expected, that the ice water content decreases with the temperature, ranging from about $11 \mathrm{mg} / \mathrm{m}^{3}$ near $-38^{\circ} \mathrm{C}$ to $3 \mathrm{mg} / \mathrm{m}^{3}$ below $-53^{\circ} \mathrm{C}$. A similar trend is observed for the effective diameter which decreases from about $50 \mu \mathrm{m}$ to $25 \mu \mathrm{m}$ in the range of temperature considered. This feature is consistent with previous observations in cirrus by Francis et al. [1998] although their effective radius values were overestimated because small particles were neglected. On the other hand our Deff results are somewhat higher than the values reported by Boudala et al. [2002] for data obtained in high-latitude clouds near $-40^{\circ} \mathrm{C}$. These brief comparisons with previous works highlight the difficulty of obtaining an accurate measurement of the effective size of ice crystals; indeed, suitable instrumentation is needed before this can be remedied.

[20] The observed extinction coefficients (around $0.5 \mathrm{~km}^{-1}$ ) also decrease for temperatures lower than $-53^{\circ} \mathrm{C}$. Differences with the extinction measurements reported by Heymsfield and McFarquhar [2002] may be attributed to the significant contribution of small ice crystals as indicated above and also to the different instruments used to make the measurements [see, e.g., Korolev et al., 2001]. The ice particle concentration (ranging from 1 to $3 \mathrm{~cm}^{-3}$ ) exhibits no apparent relationship with temperature. The asymmetry parameter values show rather small variations (median between 0.777 and 0.762 ; i.e., $80 \%$ of the data of $g$ lie within 0.76 to 0.78 ). This result highlights the fairly uniform optical properties of the cirrus clouds sampled between $-33^{\circ} \mathrm{C}$ and $-60^{\circ} \mathrm{C}$ For temperatures above $-40^{\circ} \mathrm{C}$, our results agree with the $g$ values reported by Garrett et al. [2001] for arctic clouds.

[21] The results in Table 3 show a wide scatter in the microphysical properties which may be mainly caused by the natural variations of cirrus cloud properties and the limited number of flights performed. Indeed, the random uncertainties are considerably reduced with regards to those reported in Table 2 because the results address averages on many data points. In particular the natural variability may hamper the comparison of the results from the two field experiments. Nevertheless, the results of all data reported in Table 3 show that compared with the mean properties of cirrus clouds in $\mathrm{SH}$, the cirrus sampled in $\mathrm{NH}$ were characterized by a higher concentration of ice crystals $\left(2.2 \mathrm{~cm}^{-3}\right.$ versus $1.4 \mathrm{~cm}^{-3}$ respectively) and by a lower effective diameter (36 $\mu \mathrm{m}$ versus $42 \mu \mathrm{m}$ respectively). A significant contrast in extinction coefficient is also 
Table 3. Southern Hemisphere (SH) and Northern Hemisphere (NH) Campaign Median Values and Quartiles of Distributions for Three Ranges of Temperature and for All the Data

\begin{tabular}{|c|c|c|c|}
\hline Parameter $^{\mathrm{a}}$ & $\mathrm{SH}$ & $\mathrm{NH}$ & $\Delta,{ }^{\mathrm{b}} \%$ \\
\hline & \multirow{2}{*}{\multicolumn{2}{|c|}{$-33^{\circ} \mathrm{C} \leq T<-43^{\circ} \mathrm{C}$}} & \\
\hline Conc., $\mathrm{cm}^{-3}$ & & & \\
\hline $25 \%$ & 0.70 & 0.90 & \\
\hline Median & 1.59 & 2.12 & 29 \\
\hline $75 \%$ & 3.22 & 4.89 & \\
\hline \multicolumn{4}{|l|}{ IWC, $\mathrm{mg} \mathrm{m}^{-3}$} \\
\hline $25 \%$ & 4.4 & 4.2 & \\
\hline Median & 10.8 & 11.5 & 6 \\
\hline $75 \%$ & 20.1 & 22.6 & \\
\hline \multicolumn{4}{|l|}{ Ext., $\mathrm{km}^{-1}$} \\
\hline $25 \%$ & 0.23 & 0.27 & \\
\hline Median & 0.50 & 0.66 & 28 \\
\hline $75 \%$ & 0.96 & 1.33 & \\
\hline \multicolumn{4}{|l|}{ Deff., $\mu \mathrm{m}$} \\
\hline $25 \%$ & 35.9 & 31.7 & \\
\hline Median & 57.0 & 46.4 & -20 \\
\hline $75 \%$ & 89.2 & 69.5 & \\
\hline \multicolumn{4}{|l|}{ Asymmetry } \\
\hline $25 \%$ & 0.763 & 0.762 & \\
\hline Median & 0.769 & 0.768 & -1 \\
\hline $75 \%$ & 0.776 & 0.773 & \\
\hline & \multicolumn{2}{|c|}{$-43^{\circ} \mathrm{C} \leq T<-53^{\circ} \mathrm{C}$} & \\
\hline \multicolumn{4}{|l|}{ Conc., $\mathrm{cm}^{-3}$} \\
\hline $25 \%$ & 0.64 & 0.71 & \\
\hline Median & 1.71 & 2.00 & 16 \\
\hline $75 \%$ & 3.43 & 4.41 & \\
\hline \multicolumn{4}{|c|}{ IWC, $\mathrm{mg} \mathrm{m}^{-3}$} \\
\hline $25 \%$ & 3.8 & 2.5 & \\
\hline Median & 9.5 & 7.5 & -24 \\
\hline $75 \%$ & 18.1 & 16.6 & \\
\hline \multicolumn{4}{|l|}{ Ext., $\mathrm{km}^{-1}$} \\
\hline $25 \%$ & 0.24 & 0.22 & \\
\hline Median & 0.56 & 0.57 & 2 \\
\hline $75 \%$ & 0.90 & 1.19 & \\
\hline \multicolumn{4}{|l|}{ Deff., $\mu \mathrm{m}$} \\
\hline $25 \%$ & 32.1 & 25.9 & \\
\hline Median & 43.2 & 34.9 & -21 \\
\hline $75 \%$ & 69.9 & 51.9 & \\
\hline \multicolumn{4}{|l|}{ Asymmetry } \\
\hline $25 \%$ & 0.763 & 0.762 & \\
\hline Median & 0.770 & 0.768 & -1 \\
\hline \multirow[t]{2}{*}{$75 \%$} & 0.777 & 0.773 & \\
\hline & \multirow{2}{*}{\multicolumn{2}{|c|}{$-53^{\circ} \mathrm{C} \leq T<-63^{\circ} \mathrm{C}$}} & \\
\hline Conc., $\mathrm{cm}^{-3}$ & & & \\
\hline $25 \%$ & 0.31 & 1.53 & \\
\hline Median & 0.78 & 2.98 & 117 \\
\hline $75 \%$ & 1.49 & 4.60 & \\
\hline IWC, $\mathrm{mg} \mathrm{m}^{-}$ & & & \\
\hline $25 \%$ & 0.7 & 1.2 & \\
\hline Median & 2.7 & 2.7 & 0 \\
\hline $75 \%$ & 6.0 & 13.6 & \\
\hline Ext., $\mathrm{km}^{-1}$ & & & \\
\hline $25 \%$ & .09 & 0.23 & \\
\hline Median & 0.28 & 0.47 & 51 \\
\hline $75 \%$ & 0.57 & 1.15 & \\
\hline Deff., $\mu \mathrm{m}$ & & & \\
\hline $25 \%$ & 19.5 & 13.8 & \\
\hline Median & 26.8 & 20.8 & -25 \\
\hline $75 \%$ & 35.2 & 37.2 & \\
\hline Asymmetry & & & \\
\hline $25 \%$ & 0.762 & 0.758 & \\
\hline Median & 0.767 & 0.762 & -6 \\
\hline $75 \%$ & 0.774 & 0.769 & \\
\hline & & & \\
\hline Conc., $\mathrm{cm}^{-3}$ & & & \\
\hline $25 \%$ & 0.58 & 0.84 & \\
\hline Median & 1.45 & 2.23 & 42 \\
\hline
\end{tabular}

Table 3. (continued)

\begin{tabular}{lccc}
\hline Parameter $^{\mathrm{a}}$ & $\mathrm{SH}$ & $\mathrm{NH}$ & $\Delta,^{\mathrm{b}} \%$ \\
\hline $75 \%$ & 3.01 & 4.74 & \\
IWC, $\mathrm{mg} \mathrm{m}^{-3}$ & & & \\
$25 \%$ & 3.0 & 2.7 & 1 \\
$\quad$ Median & 8.1 & 8.0 & \\
$\quad 75 \%$ & 16.6 & 18.0 & \\
Ext., km & -1 & & \\
$\quad 25 \%$ & & 0.24 & \\
Median & 0.21 & 0.61 & \\
$\quad 75 \%$ & 0.49 & 1.22 & \\
Deff., & 0.94 & & \\
$25 \%$ & & 25.4 & \\
Median & 29.6 & 36.2 & \\
$75 \%$ & 42.1 & 55.9 & \\
Asymmetry & 70.5 & & \\
$25 \%$ & & 0.762 & \\
Median & 0.764 & 0.767 & \\
$75 \%$ & 0.770 & 0.773 & \\
\hline
\end{tabular}

${ }^{\mathrm{a}}$ Parameters are Conc., ice particle concentration; IWC, ice water content; Ext., extinction coefficient; Deff., effective diameter; and the asymmetry parameter.

${ }^{\mathrm{b}}$ Relative differences $\Delta=2(\mathrm{NH}-\mathrm{SH}) /(\mathrm{SH}+\mathrm{NH})$ of the data at $\mathrm{SH}$ and $\mathrm{NH}$ are also included.

evidenced with higher values in $\mathrm{NH}$ than in $\mathrm{SH}\left(0.61 \mathrm{~km}^{-1}\right.$ versus $0.49 \mathrm{~km}^{-1}$ respectively) whereas no significant differences in the ice water content were observed $\left(8 \mathrm{mg} / \mathrm{m}^{3}\right)$. It should be noted that: (i) these differences in terms of median values were also evidenced for the $25 \%$ and $75 \%$ percentiles on each considered parameter and (ii) these contrasts were systematically observed (with somewhat different percentages) in the three temperature ranges. Therefore one may conclude that for a given dynamic forcing in a similar environment (same available water vapor and subsequent $I W C$ ) the midlatitude cirrus in $\mathrm{NH}$ will be characterized by a greater concentration of smaller ice particles as compared with $\mathrm{SH}$. This is confirmed by the results in Figure 4 which show larger Deff in SH from the Deff-IWC diagram displayed in terms of median values and quartiles

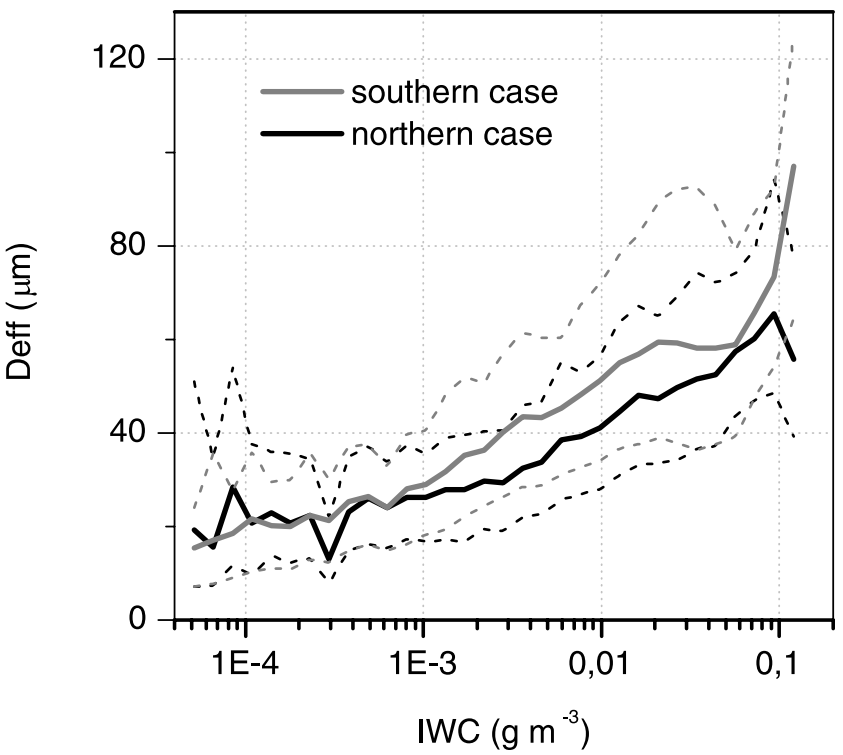

Figure 4. Effective diameter versus the ice water content in $\mathrm{SH}$ and in $\mathrm{NH}$. Solid lines represent median values, and the dashed lines are the $25 \%$ and $75 \%$ quartiles of the distributions. 


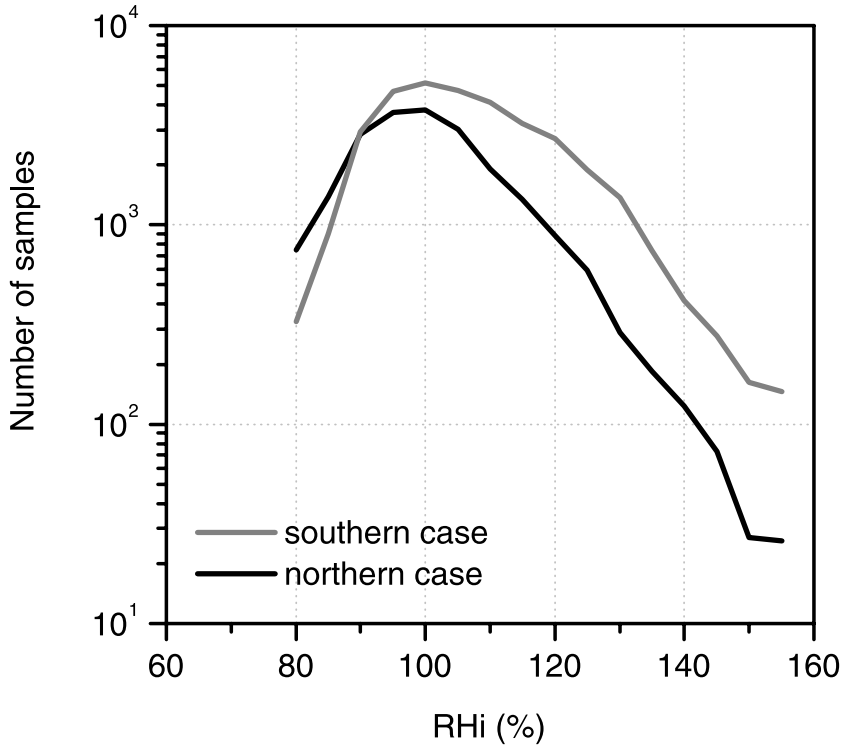

Figure 5. Frequency distributions of the number of incloud data points measured during the $\mathrm{SH}$ and $\mathrm{NH}$ field experiments versus the relative humidity over the ice.

of distributions. We note in passing that these relationships corroborate the results of Korolev et al. [2001] for data obtained in continental cirrus clouds.

[22] As a continuation of previous works on the INCA data interpretation which have recently evidenced a strong contrast in the humidity distributions [Ovarlez et al., 2002; Haag et al., 2003] as well as on freezing thresholds [Ström et al., 2003; Haag et al., 2003] we will now discuss the microphysical and optical midlatitude cirrus properties as a function of relative humidity.

\subsection{Interhemispheric Differences as a Function of Relative Humidity}

\subsubsection{Statistical Significance}

[23] Comparing our two data sets with similar environmental conditions (i.e., over a similar range of temperature and vertical velocities) at similar relative humidity with respect to ice $(\mathrm{RHi})$, our observations may give new insights into basic properties of upper tropospheric midlatitude cirrus. Therefore the data were binned into 5\% RHi intervals (from $80 \%$ to $155 \% R H i$ ). In order to assess the statistical significance of the results, the number of data points (for the two campaigns) within the individual relative humidity intervals are displayed in Figure 5. As previously indicated, the number of data points is greater for the SH than for the $\mathrm{NH}$ campaign and, in both cases, the probability of in-cloud cirrus occurrence is highest for $R H i$ between $90 \%$ and $110 \%$ [see, e.g., Ovarlez et al., 2002] with both peaking at $100 \%$. For RHi lower than $80 \%$ and higher than $135 \%$ the level of statistical significance is considerably reduced because of the low number of data points.

[24] Below we compare the results between the two field experiments in terms of microphysical and optical cirrus cloud parameters.

\subsubsection{Microphysical Properties}

[25] Figure 6 displays the median values and the quartiles of distributions binned into $5 \%$ intervals of the relative humidity with respect to ice (RHi range from $80 \%$ to
$155 \%)$, for the ice particle concentration, ice water content $(I W C)$, extinction coefficient $(E x t)$ and effective diameter (Deff, with a linear scale) respectively. Figure 6 shows that the ice particle concentration as well as the ice water content and the extinction coefficient increase monotonically with $R H i$. Similarly, the effective diameter increases with $R H i$ range from $90 \%$ to $130 \%$.

[26] Figure 6a shows that the ice particle concentration are systematically higher (by a factor of about 2) in $\mathrm{NH}$ than in SH. The median values are $0.80 \mathrm{~cm}^{-3}$ and $0.38 \mathrm{~cm}^{-3}$ at $R H i=80 \%$, and $5.75 \mathrm{~cm}^{-3}$ and $2.37 \mathrm{~cm}^{-3}$ at $R H i=130 \%$, in $\mathrm{SH}$ and $\mathrm{NH}$, respectively. For $R H i$ lower than about 90\%, IWC and Ext (Figures 6b and 6c) have similar values $\left(3.7 \mathrm{mg} / \mathrm{m}^{3}\right.$ and $0.40 \mathrm{~km}^{-1}$, respectively at $\left.R H i=90 \%\right)$. For higher $R H i$ the median $I W C$ and Ext values in NH are systematically larger than in $\mathrm{SH}$ (ratio $\sim 1.5$ ). At $R H i=$ $130 \%, I W C$ and Ext values are $21.4 \mathrm{mg} / \mathrm{m}^{3}$ and $1.30 \mathrm{~km}^{-1}$ versus $14.1 \mathrm{mg} / \mathrm{m}^{3}$ and $0.64 \mathrm{~km}^{-1}$ for $\mathrm{NH}$ and $\mathrm{SH}$, respectively. Because of the good agreement with the PMS probe optical parameter [Gayet et al., 2002a; Shcherbakov et al., 2004], the extinction coefficient values derived from the polar nephelometer measurements show similar differences between the two experiments. Larger sizes of evaporating ice crystals (i.e., $\mathrm{RHi}<100 \%$ ) are observed in $\mathrm{SH}$ than in $\mathrm{NH}$ (40 $\mu \mathrm{m}$ versus $30 \mu \mathrm{m}$ respectively, see Figure $6 \mathrm{~d}$ ). Similar Deff values $(\sim 40 \mu \mathrm{m})$ are observed at around $100-105 \%$ whereas for higher supersaturations significantly larger diameters are measured in the southern case $(57 \mu \mathrm{m}$ versus $49 \mu \mathrm{m}$ at $120 \% R H i$ respectively). We note in Figure $6 \mathrm{~d}$ the large variability of the distributions: this is mainly due to large random errors on Deff and, for $R H i$ above $130 \%$, to the low number of data points which considerably reduces the level of statistical significance (see Figure 5).

\subsubsection{Optical Properties}

[27] Figure 6e represents the median values and the quartiles of distributions of the asymmetry parameter as a function of relative humidity with respect to ice for both $\mathrm{SH}$ and NH field experiments. The results show very similar behavior for the two data sets with a slight increase for $g$ (from about 0.767 to 0.777 ) up to $130 \% R H i$, then a rather sharp decrease for higher $R H i$ with values higher in SH than in NH. These features may be compared with the Deff relationship in Figure 6d within the $80-130 \%$ RHi range. Indeed, the relationships between the asymmetry parameter and the effective diameter displayed in Figure 7 show for both field experiments that the larger the effective diameter (from $30 \mu \mathrm{m}$ to $140 \mu \mathrm{m}$ ), the higher the $g$ values (from 0.765 to 0.775 ). It should be noted that within the observed range of Deff, the $g$ variations are much smaller than those derived from the parameterizations given by $F u$ [1996]. Figure 7 also shows that there are no significant differences in the $g$ values between the two hemispheres. As the asymmetry parameter is dependent on combined effects of ice crystal shape and size, it can be concluded that there are no significant differences in crystal shapes between SH and NH. Therefore no clear indication concerning privileged ice nucleation mechanisms can be hypothesized on the basis of crystal habits.

[28] It is well known that randomly oriented ice crystals with simple geometric shape (hexagonal) cause a sharp peak in the forward scattering properties related to the $22^{\circ}$ halo (see among others, Yang et al. [2001]). Since the polar nephelometer measures the scattered energy at scattering 

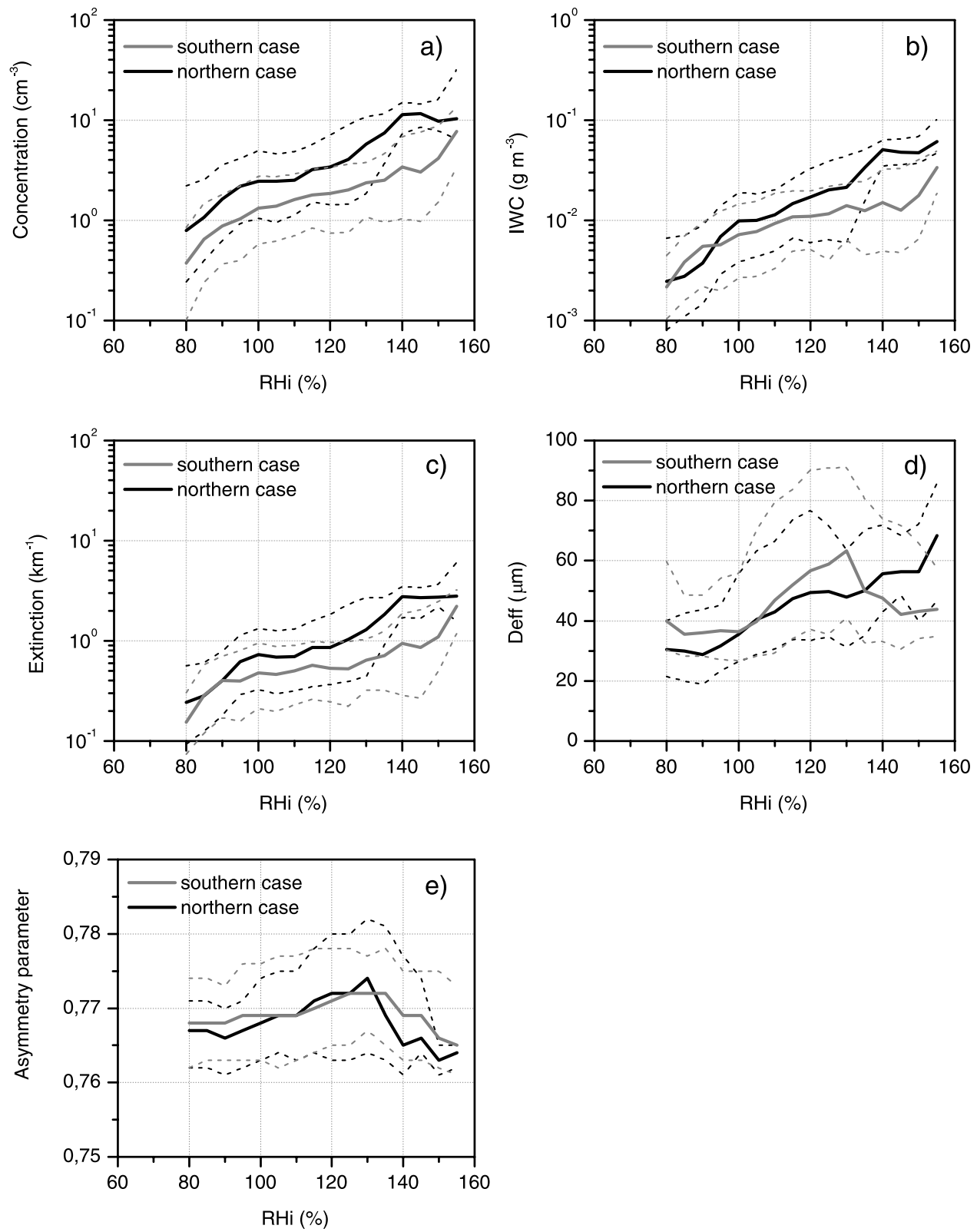

Figure 6. Microphysical and optical parameters versus the relative humidity with respect to ice for the cirrus clouds sampled in SH and in NH. Solid lines represent median values, and the dashed lines are the $25 \%$ and $75 \%$ quartiles of the distributions: (a) ice particle concentration, (b) ice water content, (c) extinction coefficient, (d) effective diameter, and (e) asymmetry parameter.

angles of $22^{\circ}$ and $18.5^{\circ}$, the ratio of the corresponding measured values provides a quantitative criteria (called hereafter halo ratio) which characterizes the $22^{\circ}$ halo feature [Auriol et al., 2001]. High halo ratio values $(>1.0)$ reveal sharp peaks that may be due to pristine ice crystals whereas imperfect crystal geometry and/or roughness of the ice surface may hamper the formation of halo [Hess et al., 1998] thereby reducing the halo ratio to 1.0 (smoothed peaks) or to smaller values $(<1.0)$ which characterize smoothed scattering phase functions with no $22^{\circ}$ halo feature.

[29] Figures 8a and 8b display, for both $\mathrm{SH}$ and $\mathrm{NH}$ field experiments, the median values and the quartiles of distributions of the halo ratio as a function of the relative humidity (with respect to ice) and the frequency distributions of the data points of the $22^{\circ}$ halo ratio respectively. The results in Figure $8 \mathrm{a}$ highlight a clear and systematic difference between the $\mathrm{SH}$ and $\mathrm{NH}$ results. In $\mathrm{NH}$ the $22^{\circ}$ halo occurs at $100 \%$ RHi versus $110 \%$ in SH. For both field experiments the relatively narrow scatter of the data indicates that the $22^{\circ}$ halo feature occurs close to these preferential $R H i$ values. It should be noted that because of a low number of data points (see Figure $8 \mathrm{~b}$ ) the level of statistical significance is considerably reduced for the halo ratio smaller than 0.4 and larger than 1.5.

[30] Figure $8 \mathrm{~b}$ shows that the two frequency distributions of the halo ratio both peak at 0.75 , a value which characterizes smoothed scattering phase functions with irregular- 


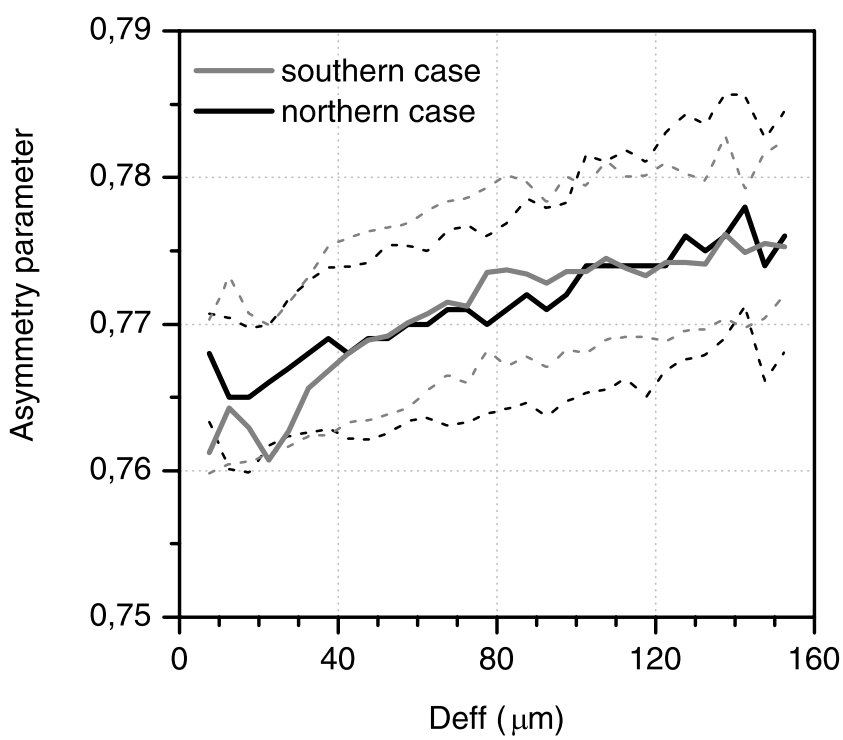

Figure 7. Asymmetry parameter versus the effective diameter ( $\mathrm{SH}$ and $\mathrm{NH}$ field experiments). Solid lines represent median values, and the dashed lines are the $25 \%$ and $75 \%$ quartiles of the distributions.

shaped ice particles [Gayet et al., 1998; Auriol et al., 2001]. By taking the above criterion (ratio $>1$ ) it may be shown that $2.6 \%$ and $3.5 \%$ of the measured scattering phase functions exhibit $22^{\circ}$ halo occurrence in $\mathrm{SH}$ and in $\mathrm{NH}$ field experiments respectively. This reveals that pristine ice crystals with a simple geometrical shape are not a common feature in midlatitude cirrus clouds. Because of the rare occurrences of the $22^{\circ}$ halo feature (only about 800 data points), the difference between $\mathrm{SH}$ and $\mathrm{NH}(2.6 \%$ and $3.5 \%$ respectively) does not appear to be statistically significant. A similar occurrence $(2 \%)$ was previously reported by Auriol et al. [2001] for data obtained in cirrus clouds sampled over southwest France. These results are consistent with the occurrence $(3 \%)$ of pristine ice particles in Arctic clouds (with temperatures lower than $-30^{\circ} \mathrm{C}$ ) reported by Korolev et al. [1999] from the analysis of CPI (Cloud Particle Imager probe) data.

[31] Extinction coefficient measurements inferred from remote measurements during INCA (MARL Lidar [Immler and Schrems, 2002]) reveal very close and low values in Punta Arenas and Prestwick $\left(0.2 \mathrm{~km}^{-1}\right)$. Much larger values were obtained from our in situ measurements with evidence of interhemispheric differences (about $0.5 \mathrm{~km}^{-1}$ and $0.6 \mathrm{~km}^{-1}$ for $\mathrm{SH}$ and $\mathrm{NH}$ respectively). Such discrepancies may be due to the fact that in situ observations address thicker clouds than remote data because the in situ extinction threshold considers values greater than $0.05 \mathrm{~km}^{-1}$. Comparisons are more successful when based on colocated measurements carried out during case studies [Gayet et al., $2002 c]$, that show a good agreement between the in situ and remote sensing data.

\section{Discussion}

[32] Though the measurements at $\mathrm{SH}$ and $\mathrm{NH}$ do not represent southern and northern midlatitudes in all respects, those at $\mathrm{SH}$ are probably more representative than those at
$\mathrm{NH}$ for the respective latitude band, because of the greater longitudinal homogeneity in the southern hemisphere. While the observed air masses always came from the Pacific over Punta Arenas area, with no continental contact for at least the last 10 days, in NH they had passed over North America and the Atlantic or the European continent in the same period before they arrived at Prestwick [Baehr et al., 2003]. For similar environmental conditions (i.e., with a very similar range of temperature and vertical velocities) and for given values of the relative humidity with respect to ice, the comparisons presented above clearly show distinct differences between the cirrus microphysical and optical properties of midlatitude cirrus clouds sampled from $\mathrm{SH}$ and $\mathrm{NH}$ field experiments. In other words, for a given value of any microphysical or optical parameter considered, a systematic difference of $10-20 \%$ in $R H i$ is evidenced between the $\mathrm{SH}$ and $\mathrm{NH}$ data sets, a value which is higher than the experimental uncertainty. Because the experimental conditions during the two field experiments were comparable (see section 3), any possible bias of the RHi measurements, that would suppress all the observed differences, should be small. In fact, the interpretation of humidity measurements by Haag et al. [2003] has established high confidence in such measurements with bias probably less than $5 \%$.

[33] Our observations corroborate the interpretation of the observed probability distributions of RHi by Ovarlez et al. [2002] who hypothesize that the clouds may not be in equilibrium in the mean and that the relaxation time to water vapor equilibrium is longer in $\mathrm{SH}$ than in NH. In addition the observed differences between the two data sets also corroborate the finding of Khvorostyanov and Sassen [1998] who found that the supersaturation increases with decreasing ice crystal concentrations. This finding may explain our very surprising observations of cases with $22^{\circ}$ halo occurrences (see Figure 8a) close to $110 \%$ and $100 \%$
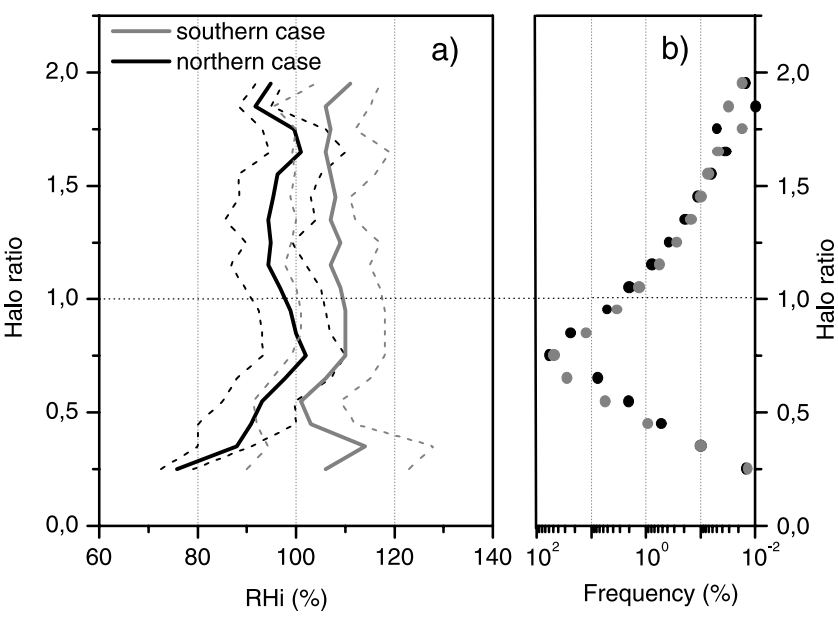

Figure 8. (a) Ratio of the values measured by the polar nephelometer at the scattering angles of $22^{\circ}$ and $18.5^{\circ}\left(22^{\circ}\right.$ halo ratio) as the function of the relative humidity with respect to ice for the $\mathrm{SH}$ and $\mathrm{NH}$ field experiments. Solid lines represent median values, and the dashed lines are the $25 \%$ and $75 \%$ quartiles of the distributions. (b) Frequency distributions of the data points of the $22^{\circ}$ halo ratio for both $\mathrm{SH}$ and $\mathrm{NH}$ field experiments. 
RHi in $\mathrm{SH}$ and $\mathrm{NH}$, respectively. Further results (not shown here) reveal high values of the $22^{\circ}$ halo ratio in regions with very low vertical wind speed, where mostly bullet-rosette ice crystal shapes are observed (from 2D-C image analysis). The highly regular crystals responsible for halo phenomena seem to result from regular and slow crystal growth which is favored by the low ice supersaturations at low updraft velocities [Heymsfield, 1986; Pruppacher and Klett, 1997].

[34] The RHi contrasts $(10-20 \%)$ which we see in the comparison of microphysical and optical cirrus properties between $\mathrm{SH}$ and $\mathrm{NH}$ may be related to the analyses of the same data by Haag et al. [2003] who highlight the interhemispheric differences in cirrus cloud freezing thresholds. The RHi values for onset of clouds in $\mathrm{NH}$ is about $20 \%$ lower than in $\mathrm{SH}$ and this difference appears to control the different occurrence of cirrus clouds [Ström et al., 2003]. The observed difference in freezing thresholds may be caused by different aerosol chemical or morphological properties in the two hemispheres. The $\mathrm{SH}$ threshold is consistent with homogeneous freezing whereas the $\mathrm{NH}$ threshold indicates heterogeneous ice formation [Haag et al., 2003].

[35] Can these findings explain the differences in the mean microphysical and optical properties of midlatitude cirrus summarized in Table 3? We recall that no significant differences in the ice water content are observed and that the distributions of $w$ and $T$ are remarkably similar in both field campaigns. This signifies that the $I W C$ is controlled not by the aerosol freezing properties but rather by the advection of water vapor and the subsequently available condensable water [Ström et al., 2003]. The higher number of particles with smaller diameter (at same $I W C$ ) observed in $\mathrm{NH}$ may be explained by lower freezing thresholds according to the numerical simulations of Kärcher and Lohmann [2002] who found that the number of pristine ice crystals is modulated by the onset of cirrus formation. Nevertheless, we cannot reach definite conclusions about the interpretation of our results because the effect of the greater small-scale variability of vertical velocity evidenced during the NH measurements has not been assessed [Kärcher and Ström, 2003]. Indeed, these authors emphasized the importance of variations in vertical velocity for the formation of ice particles. Our conclusions are also hampered by (i) the random uncertainties concerning the natural variations of the cirrus cloud properties that are much larger than the observed differences in cirrus cloud microphysical and optical properties and (ii) insufficient understanding as yet of the actual freezing mechanisms in cirrus clouds.

\section{Conclusions}

[36] Measurements of microphysical and optical cirrus properties were performed in the upper troposphere at midlatitudes at temperatures between $-33^{\circ} \mathrm{C}$ and $-60^{\circ} \mathrm{C}$ during the southern and northern INCA campaigns. Compared with the mean properties of cirrus clouds in the $\mathrm{SH}$, the cirrus sampled in the $\mathrm{NH}$ exhibit a higher concentration of ice crystals, a lower effective diameter, and higher values for the extinction coefficient. These results are in qualitative agreement with the observations of Ström and Ohlsson [1998] who observed enhanced crystal number densities in regions where the cloud particles contained elevated levels of absorbing material taken as a proxy for anthropogenic influence. Kristensson et al. [2000] found that the effective diameter is $10-30 \%$ smaller in polluted cirrus. We presented the first measurements of the asymmetry parameter in midlatitude cirrus clouds at temperatures between $-33^{\circ} \mathrm{C}$ and $-60^{\circ} \mathrm{C}$. The results highlight rather uniform particle scattering properties ( $g$ mostly ranging from 0.76 to 0.78 ) with small differences between $\mathrm{SH}$ and $\mathrm{NH}$ (mean values 0.770 versus 0.767 , respectively). No significant differences in crystal shape were evidenced between the two data sets and pristine ice crystals with a simple geometrical shape are not a common feature (around 3\% of occurrence) in the midlatitude cirrus clouds sampled during the two INCA field experiments.

[37] Obviously, these differences may not be representative for all northern and southern hemispheres cirrus properties as a whole because our in situ measurements covered only limited areas and periods of observations. Furthermore, our analysis does not consider the cases with very small ice particle concentrations (detected by the CVI probe) which are found to form at low synoptic-scale updraft speeds [Kärcher and Ström, 2003]. We recall that our database was cleared of cirrus cases characterized by very high crystal densities (wave-cirrus and anvil-cirrus). Therefore our observations address ice crystals which are associated with the mesoscale variability, as also analyzed by Kärcher and Ström [2003].

[38] At similar environmental conditions (i.e., for very similar temperature and dynamical properties), the results clearly show a systematic $R H i$ difference of $10-20 \%$ between the $\mathrm{SH}$ and $\mathrm{NH}$ data sets whatever the considered parameter. These contrasts can be related to cirrus freezing threshold differences, with onset of clouds in $\mathrm{NH}$ at about $20 \%$ lower RHi than in SH [Haag et al., 2003]. The large random uncertainties of individual microphysical measurements may be of reduced importance in the mean values taken over all data from the two campaigns. Nevertheless, conclusions about the interpretation of our results are hampered by the large natural variability of cirrus cloud properties and the limited number of flights performed. Our understanding is still insufficient to decide whether the differences between $\mathrm{NH}$ and $\mathrm{SH}$ are due to different freezing mechanisms or due to the small but potentially important differences in small-scale temperature and velocity variability.

[39] The observations obtained during the INCA experiments may be used in future studies for further investigation. In particular, the data may guide modeling of the competition between different types of freezing nuclei. Mesoscale modeling is needed to learn more about the vertical velocity field in the upper troposphere over the entire globe in a climatological sense, to assess potential regional dynamical effects on cirrus formation and subsequently on microphysical properties. From the experimental point of view, improvements are needed for a better description of ice crystal characteristics particularly with respect to size and shape in the diameter range from 20 to $100 \mu \mathrm{m}$. These particle sizes dominate the properties of midlatitude cirrus clouds in terms of bulk, effective size parameters and optical properties. New techniques should be used for a better and direct description of the chemical composition of the aerosols. Furthermore, in situ measure- 
ments of vertical airspeed components should be improved in terms of both accuracy and resolution as this parameter has been recognized as being extremely sensitive in controlling cirrus formation.

\section{Appendix A: Evaluation of the Errors of Microphysical Measurements}

\section{A1. FSSP-300 Measurements}

[40] The measurement uncertainties associated with this probe have been described by Baumgardner et al. [1992].

\section{A1.1. Particle Concentration}

[41] Because the concentration of particles (larger than $3 \mu \mathrm{m})$ in cirrus clouds is typically $<5 \mathrm{~cm}^{-3}$ the deadtime/ coincidence errors are less than $0.1 \%$. Binomial sampling theory predicts sampling errors of about $25 \%$ for a particle concentration of $5 \mathrm{~cm}^{-3}$ (20 particles sampled on an average of $5 \mathrm{sec}$.). Uncertainties of the sample volume have been evaluated to $20 \%$. Therefore the 'root-sumsquare' (RSS) of these uncertainties leads to an expected uncertainty of about $30 \%$ concerning the particle concentration measurement.

\section{A1.2. Particle Size}

[42] The size measurement error $(\approx 35 \%)$ is the RSS error of uncertainty contributions from time response and laser variations $(15 \%)$, temperature sensitivity of the photodetectors $(5 \%)$, shape asphericity, which appears greater than the value suggested by Baumgardner et al. [1992], (25\% against $10 \%$ ), and by taking into account the additional error of $20 \%$ due to the fact that the uncertainty varies with the size channel and therefore with the relative shape of the size distribution.

\section{A1.3. Extinction and Ice Water Content}

[43] The extinction coefficient (Ext) and IWC are proportional respectively to:

$$
\text { Ext } \propto \mathrm{Q} \mathrm{N} \mathrm{D}^{2} \text { and IWC } \propto \mathrm{N} \mathrm{D}^{3}
$$

with Q: extinction efficiency, $\mathrm{N}$ : particle concentration, D: particle size with uncertainties of $5 \%, 30 \%$ and $35 \%$ respectively. The RSS errors of these uncertainty contributions lead to extinction coefficient and IWC uncertainties of about $60 \%$ and $70 \%$ respectively.

\section{A2. PMS 2D-C Measurements}

[44] The errors of 2D-C measurements are difficult to evaluate when the instrument is used at high airspeed $(170 \mathrm{~m} / \mathrm{s})$ in cirrus clouds (ice particles). Nevertheless, the airspeed corrections applied on the first channels allow to obtain rather good agreement with other measurements (FSSP-300 and polar nephelometer) and therefore the uncertainties are significantly reduced. In order for some rough estimates to be evaluated we hypothesize a total error of $50 \%$ for the concentration measurements. Size errors due to the electronic response time $(10 \%)$ and additional error of $20 \%$ due to the fact that the uncertainty varies with the relative shape of the size distribution lead to size uncertainties of approximately $25 \%$. Furthermore, we assume error of mass-size relationship (A) of $50 \%$ [Darlinson and Brown, 1988].
[45] The extinction coefficient (Ext) and IWC are proportional respectively to:

$$
\text { Ext } \propto \mathrm{QN} \mathrm{D}^{2} \text { and IWC } \propto \mathrm{N} \mathrm{A} \mathrm{D}^{3}
$$

with Q: extinction efficiency, N: particle concentration, D: particle size and A: mass-size relationship. The RSS errors of the above uncertainty contributions lead to extinction and IWC uncertainties of about $60 \%$ and $75 \%$ respectively.

[46] Acknowledgments. This work was partially funded by the European Union contract EVK2-CT-1999-00039, by DLR within the project PAZI, and by a grant from the CNRS/PATOM committee. Thanks are due to our INCA colleagues for their helpful contribution to the experiments. We are very grateful to the members of the DLR who operated the Falcon aircraft during the two experiments. We acknowledge all the people who supported us at Punta Arenas and Prestwick airports both before and during the campaigns. The detailed comments of R. Baumann (DLR) were greatly appreciated. We thank J.-F. Fournol and C. Gourbeyre (LaMP) for their technical assistance. We would like to give recognition to B. Guillemet and C. Duroure (LaMP) for helpful discussions. We thank $\mathrm{K}$. James who reviewed the manuscript. We thank anonymous reviewers who made important comments which strengthened the manuscript.

\section{References}

Arnott, W. P., D. Mitchell, C. Schmitt, D. Kingsmill, and D. Ivanov (2000), Analysis of the FSSP performance for measurement of small crystal spectra in cirrus, paper presented at 13th International Conference on Clouds and Precipitation, Int. Comm. on Clouds and Precip., Reno, Nev., 14-18 Aug.

Auriol, F., J.-F. Gayet, G. Febvre, O. Jourdan, L. Labonnote, and G. Brogniez (2001), In situ observations of cirrus cloud scattering phase function with $22^{\circ}$ and $46^{\circ}$ halos: Cloud field study on 19 February 1998, J. Atmos. Sci., $58,3376-3390$

Baehr, J., H. Schlager, H. Ziereis, P. Stock, P. van Velthoven, R. Busen, J. Ström, and U. Schumann (2003), Aircraft observations of $\mathrm{NO}, \mathrm{NO}_{\mathrm{y}}$, $\mathrm{CO}$, and $\mathrm{O}_{3}$ in the upper troposphere from $60^{\circ} \mathrm{N}$ to $60^{\circ} \mathrm{S}$ : Interhemispheric differences at mitlatitudes, Geophys. Res. Lett., 30(11), 1598, doi:10.1029/2003GL016935.

Baumgardner, D. (1983), An analysis and comparison of five water droplet measuring instruments, J. Clim. Appl. Meteorol., 22, 891-910.

Baumgardner, D., and A. Korolev (1997), Airspeed corrections for optical array probe sample volume, J. Atmos. Oceanic Technol., 14, 1224-1229.

Baumgardner, D., J. E. Dye, B. W. Gandrup, and R. G. Knollenberg (1992), Interpretation of measurements made by the Forward Scattering Spectrometer Probe (FSSP-300) during the airborne arctic stratosphere expedition, J. Geophys. Res., 97(D8), 8035-8046.

Bögel, W., and R. Baumann (1991), Test and calibration of the DLR Falcon wind measuring system by maneuvers, J. Atmos. Oceanic Technol., 8, $5-18$.

Borrmann, S., B. Luo, and M. Mishchenko (2000), Application of the T-matrix method to the measurement of aspherical (ellipsoidal) particles with forward scattering optical counters, J. Aerosol Sci., 31(7), 789-799. Boucher, O. (1999), Air traffic may increase cirrus cloudiness, Nature, 397, $30-31$.

Boudala, F. S., G. A. Isaac, Q. Fu, and S. T. Cober (2002), Parameterization of effective ice particle size for high-latitude clouds, Int. J. Climatol., 22, $1267-1284$

Darlinson, A. G., and P. R. Brown (1988), The use of automatic particle recognition to improve the determination of bulk quantities from PMS $2-\mathrm{D}$ probe data in cirrus, paper presented at 10th International Cloud Physics Conference, Int. Assoc. of Meterorol. and Atmos. Phys., Bad Homburg, Germany, 15-20 Aug.

Francis, P. N., P. Hignett, and A. Macke (1998), The retrieval of cirrus cloud properties from aircraft multi-spectral reflectance measurements during EUCREX'93, Q. J. R. Meteorol. Soc., 124, 1273-1291.

$\mathrm{Fu}$, Q. (1996), An accurate parameterization of the solar radiative properties of cirrus clouds for climate models, J. Clim., 9, 2058-2082.

Garrett, T. J., P. V. Hobbs, and H. Gerber (2001), Shortwave, single-scattering properties of arctic clouds, J. Geophys. Res., 106(D14), 15,15515,172 .

Gayet, J.-F., G. Febvre, G. Brogniez, H. Chepfer, W. Renger, and P. Wendling (1996), Microphysical and optical properties of cirrus and contrails: Cloud field study on 13 October 1989, J. Atmos. Sci., 53, 126-138.

Gayet, J.-F., O. Crépel, J.-F. Fournol, and S. Oshchepkov (1997), A new airborne polar nephelometer for the measurements of optical and micro- 
physical cloud properties. Part I: Theoretical design, Ann. Geophys., 15, $451-459$

Gayet, J.-F., F. Auriol, S. Oshchepkov, F. Schröder, C. Duroure, G. Febvre, J.-F. Fournol, O. Crépel, P. Personne, and D. Daugeron (1998), In situ measurements of the scattering phase function of stratocumulus, contrails and cirrus, Geophys. Res. Lett., 25, 971-974.

Gayet, J.-F., F. Auriol, A. Minikin, J. Ström, M. Seifert, R. Krejci, A. Petzold, G. Febvre, and U. Schumann (2002a), Quantitative measurement of the microphysical and optical properties of cirrus clouds with four different in situ probes: Evidence of small ice crystals, Geophys. Res. Lett., 29(24), 2230, doi:10.1029/2001GL014342.

Gayet, J.-F., S. Asano, A. Yamazaki, A. Uchiyama, A. Sinyuk, O. Jourdan, and F. Auriol (2002b), Two case studies of winter continental-type water and mixed-phase stratocumuli over the sea: 1 . Microphysical and optical properties, J. Geophys. Res., 107(D21), 4569, doi:10.1029/ 2001JD001106.

Gayet, J.-F., F. Immler, F. Auriol, A. Minikin, A. Petzold, J. Ovarlez, and J. Ström (2002c), Microphysical and optical properties of a wave-cirrus cloud sampled during the INCA experiment, paper presented at 11th Conference on Cloud Physics, Am. Meteorol. Soc., Ogden, Utah, 3-7 June.

Gerber, H., Y. Takano, T. J. Garrett, and P. V. Hobbs (2000), Nephelometer measurements of the asymmetry parameter, volume extinction coefficient and backscatter ratio in arctic clouds, J. Atmos. Sci., 57, 3021-3034.

Haag, W., B. Kärcher, J. Ström, A. Minikin, U. Lohmann, J. Ovarlez, and A. Stohl (2003), Freezing thresholds and cirrus cloud formation mechanisms inferred from in situ measurements of relative humidity, Atmos. Chem. Phys., 3, 1791-1806.

Hess, M., R. B. Koelemeijer, and P. Stammes (1998), Scattering matrices of imperfect hexagonal ice crystals, J. Quant. Spectrosc. Radiat. Transfer, 60, 301-308.

Heymsfield, A. J. (1972), Ice crystal terminal velocities, J. Atmos. Sci., 29, $1348-1366$

Heymsfield, A. J. (1986), Ice particles observed in a cirriform cloud at $-83^{\circ} \mathrm{C}$ and implications for polar stratospheric clouds, J. Atmos. Sci. $43,851-855$

Heymsfield, A. J., and G. M. McFarquhar (2002), Mid-latitude and tropical cirrus: Microphysical properties, in Cirrus, edited by D. K. Lynch et al., pp. 78-101, Oxford Univ. Press, New York.

Heymsfield, A. J., and L. M. Miloshevich (1995), Relative humidity and temperature influences on cirrus formation and evolution: Observations from wave clouds in FIRE II, J. Atmos. Sci., 52, 4302-4326.

Heymsfield, A. J., and J. L. Parrish (1978), A computational technique for increasing the effective sampling volume of the PMS two-dimensional particle size spectrometer, J. Appl. Meteorol., 17, 1566-1572.

Immler, F., and O. Schrems (2002), LIDAR measurements of cirrus clouds in the northern and southern midlatitudes during INCA $\left(55^{\circ} \mathrm{N}, 53^{\circ} \mathrm{S}\right)$ : A comparative study, Geophys. Res. Lett., 29(16), 1809, doi:10.1029/ 2002GL015077.

Kärcher, B., and U. Lohmann (2002), A parameterization of cirrus cloud formation: Homogeneous freezing including effects of aerosol size, J. Geophys. Res., 107(D23), 4698, doi:10.1029/2001JD001429.

Kärcher, B., and J. Ström (2003), The roles of dynamical variability and aerosols in cirrus cloud formation, Atmos. Chem. Phys., 3, 823-838.

Khvorostyanov, V. I., and K. Sassen (1998), Cirrus cloud simulation using explicit microphysics and radiation. Part II: Microphysics vapor and ice mass budgets, optical and radiative properties, J. Atmos. Sci., 55, $1822-$ 1845.

Korolev, A. V., G. Isaac, and J. Hallett (1999), Ice particle habits in Arctic clouds, Geophys. Res. Lett., 26, 1299-1302.

Korolev, A. V., G. A. Isaac, I. P. Mazin, and H. W. Baker (2001), Microphysical properties of continental clouds from in situ measurements, $Q$. J. R. Meteorol. Soc., 127, 2117-2151.

Kristensson, A., J.-F. Gayet, J. Ström, and F. Auriol (2000), In situ observations of a reduction in effective crystal diameter in cirrus clouds near flight corridors, Geophys. Res. Lett., 27, 681-684.

Lawson, P., A. J. Heymsfield, S. M. Aulenbach, and T. L. Jensen (1998), Shapes, sizes and light scattering properties of ice crystals in cirrus and a persistent contrail during SUCCESS, Geophys. Res. Lett., 25, 1331 1334.

Locatelli, J. D., and P. V. Hobbs (1974), Fall speeds and masses of solid precipitation particles, J. Geophys. Res., 79, 2185-2197.

Minikin, A., A. Petzold, J. Ström, R. Krejci, M. Seifert, H. Schlager, P. van Velthoven, and U. Schumann (2003), Aircraft observations of the upper tropospheric fine particle aerosol in the Northern and Southern Hemispheres at midlatitudes, Geophys. Res. Lett., 30(10), 1503, doi:10.1029/ 2002GL016458.
Ovarlez, J., P. van Velthoven, G. Sachse, S. Vay, H. Schlager, and H. Ovarlez (2000), Comparison of water vapor measurements from POLINAT 2 with ECMWF analyses in high-humidity conditions, J. Geophys. Res., 105(D3), 3737-3744.

Ovarlez, J., J.-F. Gayet, K. Gierens, J. Ström, H. Ovarlez, F. Auriol, R. Busen, and U. Schumann (2002), Water vapour measurements inside cirrus clouds in Northern and Southern Hemispheres during INCA, Geophys. Res. Lett., 29(16), 1813, doi:10.1029/2001GL014440.

Penner, J. E., et al. (1999), Aviation and the Global Atmosphere, pp. $65-$ 120, Cambridge Univ. Press, New York.

Pruppacher, H. R., and J. D. Klett (1997), Microphysics of Clouds and Precipitation, 954 pp., Kluwer Acad., Norwell, Mass.

Randall, D. A., B. Albrecht, S. Cox, D. Johnson, P. Minnis, W. Rossow, and D. Starr (1995), On FIRE at ten, Adv. Geophys., 38, 37-177.

Raschke, E., J. Schmetz, J. Heintzenberg, R. Kandel, and R. Saunders (1990), The International Cirrus Experiment (ICE): A joint European effort, Eur. Space Agency J., 14, 193-199.

Sauvage, L., H. Chepfer, V. Trouillet, P. H. Flamant, G. Brogniez, J. Pelon, and F. Albers (1999), Remote sensing of cirrus radiative properties during EUCREX'94: Case study of 17 April 1994. Part 1: Observations, Mon. Weather Rev., 127, 504-519.

Shcherbakov, V., J.-F. Gayet, O. Jourdan, A. Minikin, and J. Ström (2004), Assessment of cirrus cloud optical and microphysical data reliability by applying the principal component analysis technique, J. Atmos. Oceanic Technol., in press.

Schröder, F., B. Kärcher, C. Duroure, J. Ström, A. Petzold, J.-F. Gayet, B. Strauss, P. Wendling, and S. Borrmann (2000), On the transition of contrails into cirrus clouds, J. Atmos. Sci., 57, 464-480.

Seifert, M., J. Ström, R. Krejci, A. Minikin, A. Petzold, J.-F. Gayet, U. Schumann, and J. Ovarlez (2003), In situ observations of aerosol particles remaining from evaporated cirrus crystals: Comparing clean and polluted cases, Atmos. Chem. Phys., 3, 1037-1049.

Starr, D. O., and D. P. Wylie (1990), The 27-28 October 1986 FIRE cirrus case study: Meteorology and clouds, Mon. Weather Rev., 118, 22592287.

Strapp, J. W., F. Albers, A. Reuter, A. Korolev, U. Maixner, E. Rashke, and Z. Vukoviv (2001), Laboratory measurements of the response of a PMS OAP-2DC, J. Atmos. Oceanic Technol., 18, 1150-1170.

Ström, J., and S. Ohlsson (1998), In situ measurements of enhanced crystal number densities in cirrus clouds caused by aircraft exhaust, J. Geophys. Res., 103(D10), 1355-1361.

Ström, J., et al. (2001), Aerosol and cirrus measurements at midlatitudes on the Southern Hemisphere: An overview based on the first INCA experiment, Air Pollut. Rep. 74, Rep. EUR 19,428 EN, Eur. Comm., Brussels.

Ström, J., et al. (2003), Cirrus cloud occurrence as function of ambient relative humidity: A comparison of observations obtained during the INCA experiment, Atmos. Chem. Phys., 3, 1807-1816.

Takano, Y., and K. N. Liou (1995), Radiative transfer in cirrus clouds. Part III: Light scattering by irregular ice crystals, J. Atmos. Sci., 52, 818-837. Yang, P., B. C. Gao, B. A. Baum, W. J. Wiscombe, Y. X. Hu, S. L. Nasiri, P. F. Soulen, A. J. Heymsfield, G. M. McFarquhar, and L. M. Miloshevisch (2001), Sensitivity of cirrus bidirectional reflectance to vertical inhomogeneity of ice crystal habits and size distributions for Moderate-Resolution Imaging Spectroradiometer (MODIS) bands, J. Geophys. Res., 106(D15), 17,267-17,291

Zerefos, C. S., K. Eleftheratos, D. S. Balis, P. Zanis, G. Tselioudis, and C. Meleti (2003), Evidence of impact of aviation on cirrus cloud formation, Atmos. Chem. Phys. Discuss., 3, 3335-3359.

Ziereis, H., et al. (2004), Uptake of reactive nitrogen on cirrus cloud particles during INCA, Geophys. Res. Lett., 31, L05115, doi:10.1029/ 2003GL018794.

J.-F. Gayet and M. Monier, LaMP, UMR/CNRS 6016, Université Blaise Pascal, 24, avenue des Landais, F-63177 Aubiere cedex, France. (gayet@opgc.univ-bpclermont.fr)

J. Ovarlez, Laboratoire de Météorologie Dynamique, CNRS/IPSL, Ecole Polytechnique, F-91128 Palaiseau cedex, France.

V. Shcherbakov, OPGC, Université Blaise Pascal, 24, avenue des Landais, F-63177 Aubiere cedex, France.

J. Ström, ITM, Stockholm University, Frescativägen 50, SE-106 91 Stockholm, Sweden.

A. Minikin, A. Petzold, and U. Schumann, Institut für Physik der Atmosphäre, DLR Oberpfaffenhofen, Postfach 1116, D-82230 Weßling, Germany.

F. Auriol, Laboratoire d'Optique Atmosphérique, UMR/CNRS 8518, UST de Lille, F-59655 Villeneuve d'Ascq cedex, France. 